\title{
SPICE ISLAND STEW: CREOLIZATION OF FOODWAYS ON COLONIAL ERA NUTMEG PLANTATIONS, MALUKU PROVINCE, INDONESIA
}

\author{
A.J. Jordan \\ Department of Anthropology, University of Washington \\ ajordan2@uw.edu
}

\begin{abstract}
The Banda Islands, in modern Indonesia's Maluku Province, were the world's sole source of nutmeg in the $16^{\text {th }}$ century. Control over the spice trade was a major goal for European powers. Consequently, the Banda Islands were a location of early disputes and colonial experimentation. After eradicating most of the indigenous population, the Dutch East India Company established a plantation system in 1621 on the islands (Hanna 1978). The plantation system fundamentally altered the lifeways of all inhabitants of the Banda Islands but there is little evidence regarding how the alterations and adaptations occurred or why. Excavations at three nutmeg plantations reveal that the inhabitants engaged with multiple strategies of subsistence and trade. By examining multiple lines of evidence including ceramic, faunal, and starch grain analysis, a more comprehensive understanding of social adaptations to colonialism can be demonstrated.
\end{abstract}

\section{BACKGROUND}

\section{The Banda Islands in Regional Context}

The Banda Islands are a group of 10 isolated volcanic islands in the Banda Sea, about $2000 \mathrm{~km}$ east of Java and $320 \mathrm{~km}$ southwest of New Guinea (Figure 1). The Bandas are part of the modern Indonesian province of Maluku, also known as the Moluccas or Spice Islands. This archipelago was an important center in widespread trade networks for millennia, both as a major supplier of the local high quality nutmeg and as a regional entrepôt for goods (Ellen 2003). The Banda Islands first entered the historical record unambiguously in AD 1304 with mention in a Chinese text. Even at this early date the islands were associated with nutmeg (Ptak 1992). The first archaeological evidence of human habitation dates to 3150 BP (Lape 2000), but evidence of human occupation on other islands in the Maluku province has been dated to 32,000 BP (Bellwood 1997: 87). The dearth of archaeological investigation in the Banda Islands suggests that the discovery of material older than $3150 \mathrm{BP}$ is likely with continued work. The date of 3150 BP coincides with the expansion of archaeological material often associated with Austronesian languages and the introduction of domesticated animals (pigs and chickens) and pottery to remote islands by means of complex watercraft technology (Bellwood 1997).

While textual evidence hints that the greater Asian world may have established sporadic contact with the Banda Islands by the $9^{\text {th }}$ Century AD, archaeological evidence suggests regular contact was definitely established by the $14^{\text {th }}$ century AD (Lape 2000). According to Ellen (2003), the Banda Islands were a major hub in broad regional trade networks by the $15^{\text {th }}$ century and Lape's (2000) archaeological evidence supports this as well. Hanna (1978: 13) describes "Chinese, Javanese, Buginese, Portuguese, and Arab traders" as present and engaged in trade on Banda in 1599. Ellen (2003) suggests that the population of the Banda islands were importing the majority of their staple carbohydrates by the $15^{\text {th }}$ century, in part to maximize nutmeg output, but also because Banda soils were not well suited to growing sago (Metroxylon sagu) and other regional starchy staples.

The Portuguese first landed in Banda in 1512 but failed to establish a permanent settlement. Regular Dutch contact by means of Dutch East India Company vessels began in 1599. The English followed in 1601. VOC agents convinced many orang kaya to sign an agreement to sell spices only to the VOC, but few orang kaya held to the conditions of the treaty. The English established an enclave on the more remote Pulau Run and Pulau Ay in 1611. Sporadic fighting between the English and Dutch over control of the islands continued until 1621, when the VOC scored a decisive victory over the English and expelled them. Bandanese inhabitants, many of whom had allied with the English were killed, enslaved, or escaped to neighboring islands, leaving an estimated 1000 people of the original 15,000 pre-colonial population. (Hanna 1978).

Jan Pieterszoon Coen, Governor-General of the VOC in the East Indies and commander of the conquest of the Bandas, planned to import burghers from the Netherlands to administer the plantations, also known as perken (perk, sing.), that were to supply the VOC with profitable nutmeg. The plantation managers, or perkeniers, were to be provided with lease-holds and a number of slaves, based on the size of the plot. The slaves were imported from other Southeast Asian Islands, India, and possibly South Africa. Provisions, such as rice, were to be provided at 


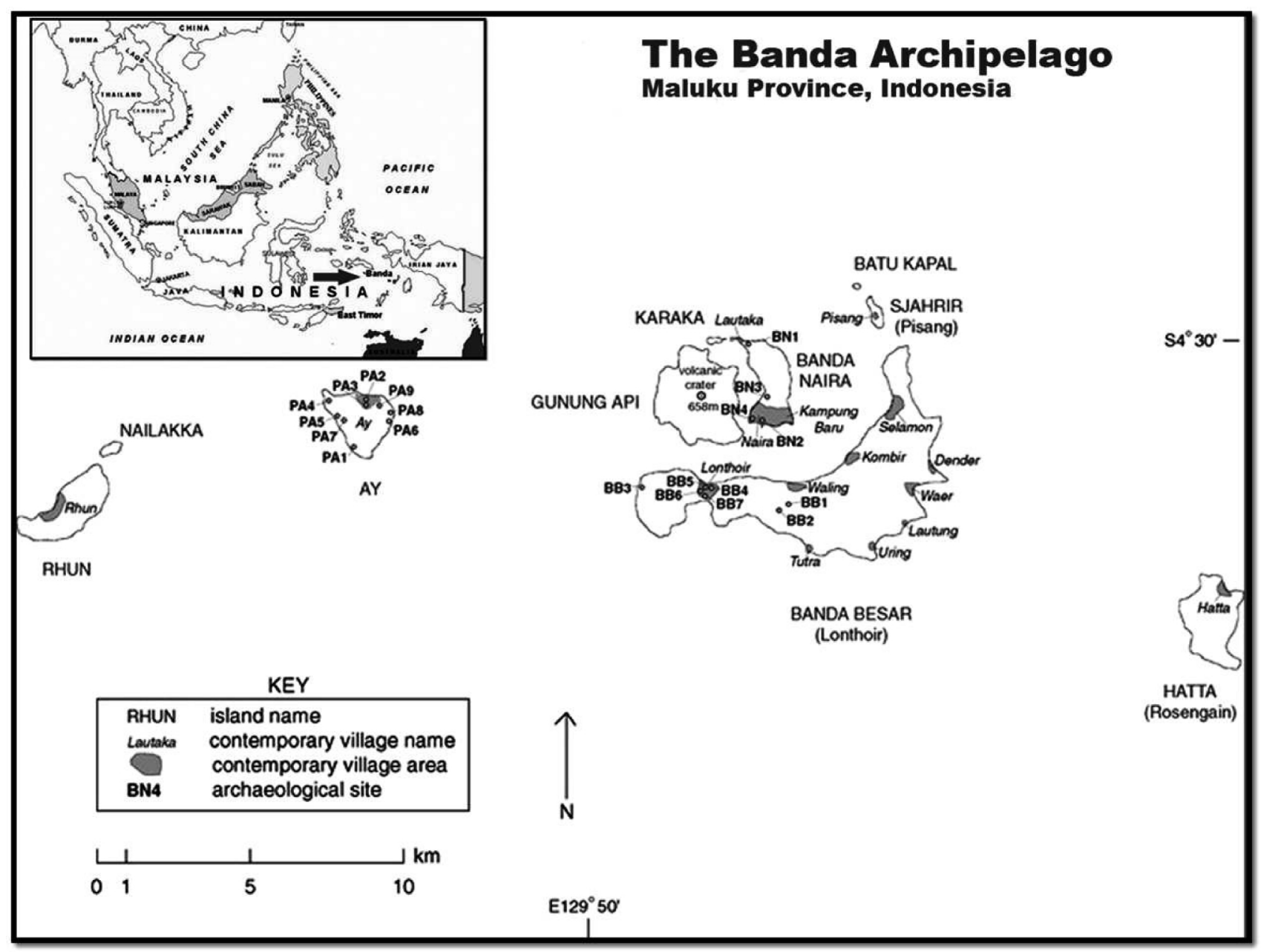

Figure 1: The Banda Islands, after Lape (2000).

cost and other goods were provided at discounted rates by the VOC in Batavia, modern Jakarata. Perkeniers were allowed to sell their harvest only to the VOC and at low fixed prices, but the perkeniers and other administrators on Banda engaged in the illicit selling of nutmeg to other sources and cheated the VOC by giving them inferior nutmeg at the superior price. These corrupt practices appear to have started in Banda and traveled down the trade supply line to Amsterdam. Perkeniers also engaged in inter-island trade to increase potential for profit. Many perkeniers were often deeply in debt to Chinese, Arab, and other European traders, able to survive only with continued infusions of capital from the VOC and, later, the Dutch government. (Hanna 1978).

The degree of creolization, according to historic records, is disputed. The dearth of available European women ensured that the perkeniers took marriage partners from the enslaved population, after they had converted to Christianity, and "exslaves [sic] mothered Dutch children" (Hanna 1978: 64). However, Loth (1998: 24) claims that creolization was slow to develop due to a high mortality rate and high level of escapism among enslaved workers.
Little detailed information on the daily lives of the imported workers is available in the historical documents. What information does exist suggests a relatively low work burden (compared to other plantation crops such as sugar or cotton) and a contest between the perkeniers and the VOC over control of labor. For instance, Winn (2010) notes that the perkeniers would often exchange elderly or poor-performing privately owned enslaved workers that were employed in domestic duties for heartier workers that were intended to work on the nutmeg plantations. Nutmeg harvesting is not as labor intensive an activity as other plantation-based agriculture. As a tree crop, nutmeg did not require the same kind of yearly planting and harvesting as did sugar, cotton, or rice. The nutmeg fruit ripens and exposes the mace-covered seed, which can then be plucked from the tree with a long-handled bamboo basket. Little subsequent processing is required. The nutmeg and mace then need to be separated from each other and any fruit remnants are removed by drying. Finally, the nutmeg and mace are packaged for export. During harvest season, many workers are needed to gather and process the spices for export, but little work needs to be performed during non-harvest times. Thus workers were hired out for municipal projects, used as sailors for 
private trading expeditions (outside the VOC control), encouraged to tend garden plots or fish to supplement VOC rations, or other work that directly benefited the perkeniers at the expense of the VOC (Winn 2010). Furthermore, due to the small land mass and remote location of the Banda Islands, workers did not have to be as closely monitored for fear of escape as in other locations, although escapism was a problem (Hanna 1978). As Winn (2010) notes, enslaved workers were not kept separate from non-enslaved populations on the Banda Islands allowing for cultural exchange and incorporation.

The VOC went bankrupt in 1800 and control of the company's holding went to the Netherlands government. This transfer of power eventually allowed perkeniers to become freeholders and dispose of their land as they would. The transfer also removed all monopoly restrictions, allowing nutmeg to be sold to the highest bidder. Due to increased competition from other nutmeg growing locations, this did not improve the perkeniers' prospects as much as they had expected. Most continued to accrue debts with no ability to repay them. The Netherlands government abolished slavery in 1860 and many former slaves left Banda to find work elsewhere (Hanna 1978). Contract workers, mainly from Java, were imported to work on the perks at this time and many of these workers stayed in the islands when their contract expired (Hanna 1978). Winn (2010) notes that the majority of oral history about plantation work in the Banda Islands dates to this contract worker period.The period of slavery under the VOC and Netherlands East Indies government does not feature in the oral history of the contemporary population who informed Winn's research.

By the early $20^{\text {th }}$ Century, the Bandas were considered a playground of the idle rich and sufficiently removed from the modern world to safely house political prisoners, including the Mohammed Hatta, Indonesia's first Vice President. The Pacific War (1941-45) damaged nutmeg groves and, with Indonesian independence, all Dutchowned land in Banda was nationalized and most of the remaining perkeniers emigrated to the Netherlands or elsewhere. Today, nutmeg harvesting has returned to the pre-colonial model with individuals harvesting from trees they claim. There is currently a collective that buys nutmegs from individual harvesters and sells to wholesalers. This modern system may more accurately reflect precolonial harvesting traditions (Winn 2002).

Historical archaeological research often focuses on North America, but Deetz (1991) called for more cross cultural studies of the different responses to European colonialism. The Banda Islands provide an excellent case study to compare to the more widely known episodes of colonization in the New World due to their contemporaneity with early New World plantations and imported enslaved labor. While much archaeological work has been conducted on North American plantations in an effort to identify the cultural adaptations experienced by enslaved people, the European colonizers, and Native American populations, there is scant material on Asian plantations. Due to the wealth of material available based on North
American studies, models were borrowed from previous studies of New World plantations in order to investigate adaptations to colonization.

The focus on plantations in the Banda Islands, as opposed to forts or other settlements, is due to a variety of reasons. Plantations, according to Stoler (1985: 2) "were virtual laboratories for technical and social experimentation. They were also microcosms of the colonial...effort... in which racial, class, ethnic, and gender hierarchies were manipulated, contested, and transformed." Previous research on ethnogenesis and foodways has been conducted on colonial-era plantations in the Americas, making plantations especially useful for comparison. The focus of investigation was further narrowed to foodways because, as Jolley (1983: 71) notes, "Differences in dietary patterning may reflect ethnicity...[and] Differences in social and ideological systems are reflected in dietary practices." Because using only one line of evidence can yield biased results, both faunal and floral data were selected for analysis - the latter starch grain residue from ceramic vessels. The combination of floral, faunal, and ceramic analysis can provide a more comprehensive view of the plantation economy. Starch grains were chosen as the sole botanical line of evidence for a variety of reasons. Primarily because starchy staples, such as sago and rice, were described as being preferred by different ethnic populations in the historic records (Ellen 2003) and their presence or absence could be related to choice or economic availability. Secondarily because earthenware was expected, based on prior excavation, to be ubiquitous in the archaeological record and starch grains tend to preserve well on earthenware (Barton and Torrence 2006). Flotation of sediment samples was not realistic in these remote islands based on Lape's experience in 1999 (P. Lape, pers. comm.). Fresh water is limited and should be reserved for human consumption. While sea water could have been used for flotation at the beachside locations, it would have been impractical to transport enough water to the upland site. Based on these logistical, and also financial, constraints, I felt it would be best to limit myself to one line of botanical evidence that would not require field processing and that could be extracted from excavated artifacts upon return to the US.

Perken were established on three of the Banda Islands, but this research was conducted on only one island, Banda Besar, which has the advantage of removing inter-island environmental differences as potential complicating factors. For instance, of the remaining two islands with nutmeg plantations, Pulau Ay is a limestone island with no ground water and Banda Neira is the main port. The different soil on Pulau Ay might affect plants available and the lack of water might affect the ability to raise livestock. Pulau Ay also requires a $15 \mathrm{~km}$ boat voyage over open ocean from Banda Neira, while Banda Besar is only 2.5 $\mathrm{km}$. Thus, depending on the season, reaching Pulau Ay is a treacherous voyage which might impact access to imported resources. Banda Neira is the main port and would have had access to all imported materials before the other 
islands which might impact the amount of resources

\section{MODELS}

Multiple interpretations of faunal and ceramic remains associated with enslaved workers have been presented in the archaeological literature on New World plantations. For instance, Franklin (2001) has argued that the remains of wild game at workers' cabins at the Rich Neck plantation in Virginia were the result of enslaved peoples asserting a social identity On the other hand, Hilliard (1988) argued these wild food choices were a result of the economic situation, as similar remains were found at the houses of Anglo-Americans of the lower economic classes. At a southeastern US plantation, Reitz et al. (1985) suggest that small game and fish predominated enslaved workers' assemblages because these resources could easily be trapped with unmanned snares and therefore had low search and handling time, whereas large game, such as deer, were not found in slaves' middens due to lack of access to firearms and high search and handling costs. Still others (e.g., Scott 2001: 687), attribute the existence of the same species of wild game in both the slaves' assemblage and main house assemblage as reflecting a "syncretic merging of two food traditions."

In these contexts, it is unclear whether the patterns of resources in worker contexts are a result of ethnic identity or economic situation. Broadening the scope of investigation to colonial plantations outside the Americas may contribute to a greater understanding of how foodways and ethnicity interact. As the previous examples indicate, three main models have been used to explain the distribution of material culture associated with food in plantation settings: energetic efficiency (from optimal foraging theory), power/ resistance, and creolization. Optimal foraging theory is an evolutionary model that assumes the maximization of nutrient acquisition will enhance reproductive fitness (Winterhalder and Smith 2008). Thus, the addition of wild game to supplement insufficient rations would increase a worker's reproductive fitness. Drawing on Foucault (1979) and Wolf (1982), among others, some authors interpret the existence of wild game in enslaved workers' assemblages to be the result of an active resistance to the dominant hegemony by asserting their own social identity (e.g., Franklin 2001). Creolization, originally from linguistic theory, is often used as a synonym for hybridity, syncretization, or a mixing of cultures, people, and languages (Khan 2007, Stewart 2007). Creole foodways involve the mixing of cultures and ingredients, often by the use of traditional cooking techniques with novel ingredients or vice versa. In the above examples, notwithstanding historical contingencies, similar data (faunal remains) in similar contexts (southeastern US plantations) are explained by these three different models. Scott (2001: 688) comments on this dilemma: "Several different scenarios could explain differences in diet... Both economic... and ethnic food preferences played a role in food consumption by all groups on the plantation."

Faunal remains have been the focus of many studies of foodways. However, the plant-based component of the available which could skew the data. diet and cooking techniques are important aspects that can also provide evidence on ethnicity (e.g., Diehl et al. 1998, Janowitz 1993). Plant resources, especially in the form of carbohydrate staples, can also reflect differences in taste preference, economic class, or merely regional availability (Janowitz 1993). Studies of ethnicity related to faunal remains may have previously proved equivocal due to a focus on only one line of evidence. Investigating multiple lines of evidence will strengthen the identification of trends or anomalies (Gould 1980). The use of multiple lines of evidence in investigating foodways in plantation and other settings has proved fruitful in many studies (e.g., Diehl et al. 1998, Janowitz 1993, Schmitt and Zeier 1993, Voss 2008).

The Power/Resistance and Creolization models assume ethnic identity is signaled and interpreted by means of material culture, specifically food remains, including choice of raw material and processing techniques. However, the energetic efficiency model assumes the food remains are related to judicial use of available time; any association with ethnic groups is an accidental signal. The hypotheses and models are not mutually exclusive and exhaustive, in part due to overlap in resources available to inhabitants and hypotheses that have to reflect historically known behavior. Thus, while some resources are predicted to show similar distribution under two different models, it is the use of all lines of evidence that will lead to the acceptance or rejection of the model as an explanatory tool. Multiple models are being investigated as it is expected that different groups may choose different strategies or changes in the global market may necessitate a renegotiation of social forms based on a new model.

\section{Predictions}

\section{Energetic Efficiency}

Due to different time constraints, the elites are not expected to rank resources in the same way as lower ranked individuals. Workers are expected to be constrained by time available for finding non-ration foods and will thus avoid resources with high search and handling costs, regardless of caloric value. Perkeniers have no time constraints, have control over the distribution of rations, and have access to firearms (Hanna 1978). Perkeniers are predicted to have a decreased need for energetic efficiency in foraging and will not be constrained by search and handling time. Costly signaling, in the form of the acquisition of large or dangerous game (Bliege Bird and Smith 2005), may also be a factor in subsistence choices for elites. Due to foraging time constraints, workers are not expected to exhibit costly signaling in the pursuit of subsistence resources (although costly signaling may have been present in behavior or acquisition of other material culture). Plantation workers are expected to have limited access to imported goods, but their dietary remains should reflect a higher percentage of wild gathered food, possibly small game or fish reflecting snare use (Loth 1998). Large domesticated mammal, such as cow and pig, should dominate in perkenier contexts, but should not be present in 
workers' contexts. Tolerated theft (e.g., Bliege Bird and Bird 1997) is not expected as capital punishment was practiced for minor infractions in Banda (Hanna 1978). It is assumed that under the energetic efficiency model, the risk of capital punishment was too great; for other models, such as power/ resistance, capital punishment may not have been as strong a deterrent. Individual perken were allowed one or two cows for personal dairy consumption, but herds were segregated on an uninhabited island, Gunung Api. This segregation makes search and handling times and risk of capture too costly for workers in an energetic efficiency model. For starches, imported rice, with a low search and handling time, is expected to dominate both worker and perkenier contexts. Rice was distributed by perkeniers and workers had little choice in how much ration they received. However, after the rice subsidization stopped in 1824 (Hanna 1978), rice is expected to be more costly and decrease in workers' contexts. Sago is expected to have supplemented workers' rations in times of a rice ration shortage and after the subsidy ceased. Due to high handling time and poor growing conditions on the Bandas (Stark and Latinis 1992), sago is expected to have been primarily imported. The remains of ceramic sago molds would indicate imported sago. Indigenous ceramics are expected to have little time invested in decoration. Imported ceramics in workers' contexts are expected to be plainware and reflect cooking foods with a low time investment in preparation and tending, such as stews. It is expected that workers prepared food for perkeniers and would also be preparing stews. However, a larger diversity of ceramics types and sources is expected in the perkenier context due to greater access to imported goods. Individual ceramic place settings are not expected in workers' contexts; instead, communal serving dishes are expected.

\section{Power and Resistance}

If the domination/ resistance social model can explain food choice, then cultural continuity of food ways and material culture is expected, specifically reflecting foodways that are not necessarily energetically efficient. The plantation workers would resist incorporation into hegemonic world, reject introduced foodways including imported foreign foods, and attempt to maintain separate foodways. European foods and goods would be expected only in European contexts and little to no imported foods or goods would be expected in the worker's areas. If European goods or foods are found, it is expected to be a result of theft, or quotidian resistance. Theft should be limited to easily transported and hidden items. For instance, the appropriation of an entire cow is not expected, but individual cuts of meat may be easily transported and surreptitiously consumed. Due to the high cost associated with the theft of elite food (i.e., capital punishment [Hanna 1978]), this is not expected under an energetic efficiency model. With the exception of rice rations, starch residues are expected to be mutually exclusive, with Europeans and their descendants eating imported wheat or corn and workers subsisting on sago, cassava or other endemic vegetal resources. It is also expected that pig remains will be segregated to elite contexts, with workers adopting or maintaining Muslim foodways in order to distance themselves from the Christian perkeniers. Imported/ enslaved workers were not necessarily Muslim, and there is some evidence that the Dutch preferred nonMuslim workers and conversions may have been socially motivated (Ricklefs 2001). Ceramic types should also be mutually exclusive; Europeans should use imported pottery from England, the Netherlands, or other European countries, in addition to high quality Chinese porcelains. Workers, on the other hand, should use locally produced pottery or cheap regional imports. The ceramic types should also reflect a preference in cooking techniques. Due to the same broad resource categories, many of the predictions for the power/ resistance model in terms of faunal resources are similar to the optimal foraging predictions. The elites have the power to distribute rations and limit time available to workers for foraging. In the power/resistance model, more theft is expected. For instance, local fish in elite contexts are expected to be larger, on average, than those in workers contexts due to elites appropriating the catch (Loth 1998). The power/ resistance model is expected to be more pronounced in the material culture associated with food preparation and consumption, such as ceramic types and wares, than the raw materials. Imported European food stuffs (e.g., salted fish, wine, etc.) are expected in elite contexts. Cooking techniques (e.g., stew, roast, etc) should show distinct separation between perkeniers and workers. Perkeniers would accept the extra cost and investment of importing or training a worker in European style cooking and its associated ceramic styles. There should be little overlap in distribution of species and elements of faunal remains (excepting chicken and local fish). These ceramics may exhibit decorative elements that distance them from European or high status Asian ceramics. European forms, especially place settings, are expected only in elite contexts.

\section{Creolization}

Chaudenson (2001: 195) notes that "the greater the role of language in a cultural system, the more the system is influenced by the dominant social group whose language is imposed on all." In a creolization context, then, it would be expected that the group whose language was most prevalent would also have the dominant material culture. In Indonesia, the Dutch preferred the use of the Malay-based lingua franca and did not impose the use of Dutch on the colonized populations. Therefore, it is expected that European foodways would be less influential than traditional Southeast Asian foodways when foodways deviate from expected energetic efficiency. In addition, the climate of Island Southeast Asia was not as conducive to European crops as to its own endemic crops. For the creolization model, mixing of foodways and material culture is expected. The adoption of European food stuffs, preparation techniques, or serving vessels would signal a familiarity with the elites and may be adopted. 
Table 1: Predicted distribution of resources, according to each model.

\begin{tabular}{|c|c|c|c|c|c|c|}
\hline \multirow[t]{2}{*}{ Resources } & \multicolumn{2}{|c|}{ OFT } & \multicolumn{2}{|c|}{ Power/ Resistance } & \multicolumn{2}{|c|}{ Creolization } \\
\hline & Workers & Perkeneirs & Workers & Perkeneirs & Workers & Perkeneirs \\
\hline \multicolumn{7}{|l|}{ Faunal Resources } \\
\hline - Cow & - & + & - & + & $\approx$ & $\approx$ \\
\hline - $\quad$ Pig & - & + & $\neq$ & + & $\approx$ & $\approx$ \\
\hline - $\quad$ Chicken & + & - & + & - & $\approx$ & $\approx$ \\
\hline - $\quad$ Local Shellfish & + & - & + & - & $\approx$ & $\approx$ \\
\hline - $\quad$ Local Wild game (small) & + & - & + & $\neq$ & $\approx$ & $\approx$ \\
\hline \multicolumn{7}{|l|}{ Ceramics } \\
\hline - Indigenous & + & $\neq$ & + & $\neq$ & $\approx$ & $\approx$ \\
\hline - Imported Asian & - & + & - & + & $\approx$ & $\approx$ \\
\hline - Imported European & - & + & $\neq$ & + & $\approx$ & $\approx$ \\
\hline \multicolumn{7}{|l|}{ Starches } \\
\hline - $\quad$ Rice & $\approx$ & $\approx$ & - & + & $\approx$ & $\approx$ \\
\hline - $\quad$ Sago/ Cassava & + & - & + & $\neq$ & $\approx$ & $\approx$ \\
\hline - $\quad$ Maize/ Wheat & $\neq$ & + & $\neq$ & + & $\approx$ & $\approx$ \\
\hline
\end{tabular}

$\neq$ : not present

$+:$ higher $\%$ than other economic class

-: lower \% than other economic class

$\approx$ : little to no statistically significant difference in distribution

European-descendants may also adopt Asian foodways out of similar reasons, or because of mixed parentage. For the creolization model, large mammal cuts are expected to be incorporated into indigenous recipes and indigenous ingredients are expected to be incorporated into European recipes. In general, there should be overlap in distribution of faunal resources, starches, and ceramics. Ceramics associated with a specific cooking style or food production may be allocated to a new role, which may be identified by starch analysis. There may be a hierarchy of mixing with more European and less indigenous goods in elite contexts and more indigenous and less European goods in workers' contexts.

Table 1 provides a synopsis for the expected distribution of each resource category according to predictions for each model.

\section{PLANTATION SITES ON THE BANDA ISLANDS}

The three sites excavated were Ordatang, Groot Waling, and Komber (Figure 2). Most Bandanese plantations were abandoned around WWII and the structures have been re-appropriated as building material or ready-built walls for modern residences. These three sites were the best choices for excavation based on preservation and lack of modern occupation.

Ordatang (Figure 3) is located on the top of the island, along a ridge that is the remains of old caldera. Ordatang is unique amongst the perks excavated in that it was not located on a beach. Ordatang was also wholly abandoned. Groot Waling (Figure 4) is the only perk still in operation and is being run by the direct lineal descendant of the original "perkenier," Pieter van den Broeke. The van den Broeke family still harvests and processes the nutmeg in the traditional way. While the van den Broeke family still lives within the plantation compound, they have built a modern house and most of the original structures have fallen into ruin. Komber (Figure 5) is the final perk site. A school was built within the compound walls relatively recently and some of the external walls have been used for housing, but the structures at Komber maintained the highest degree of integrity compared to the remaining sites and the potential for intact subsurface deposits was anticipated.

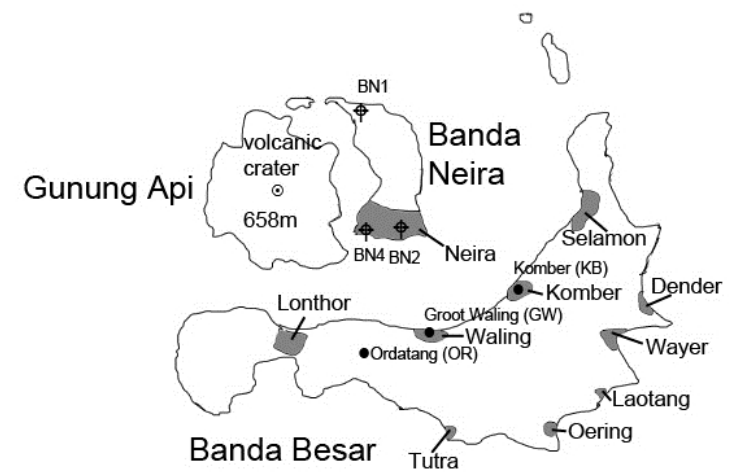

- Plantation sites

es in gray

Lape (2000) sites mentioned in text

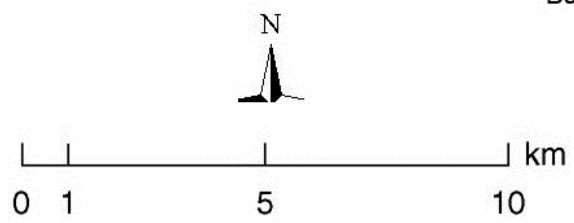

Banda Sea

Figure 2: Location of plantation sites excavated, after Lape (2000). Historically recorded villages are shaded gray, excavated perks are dots.

The plantation structures on the Banda Islands generally consist of a rectangle of continuous wall with a front and back entrance; inside this compound wall are structures using the external compound wall as the back wall 


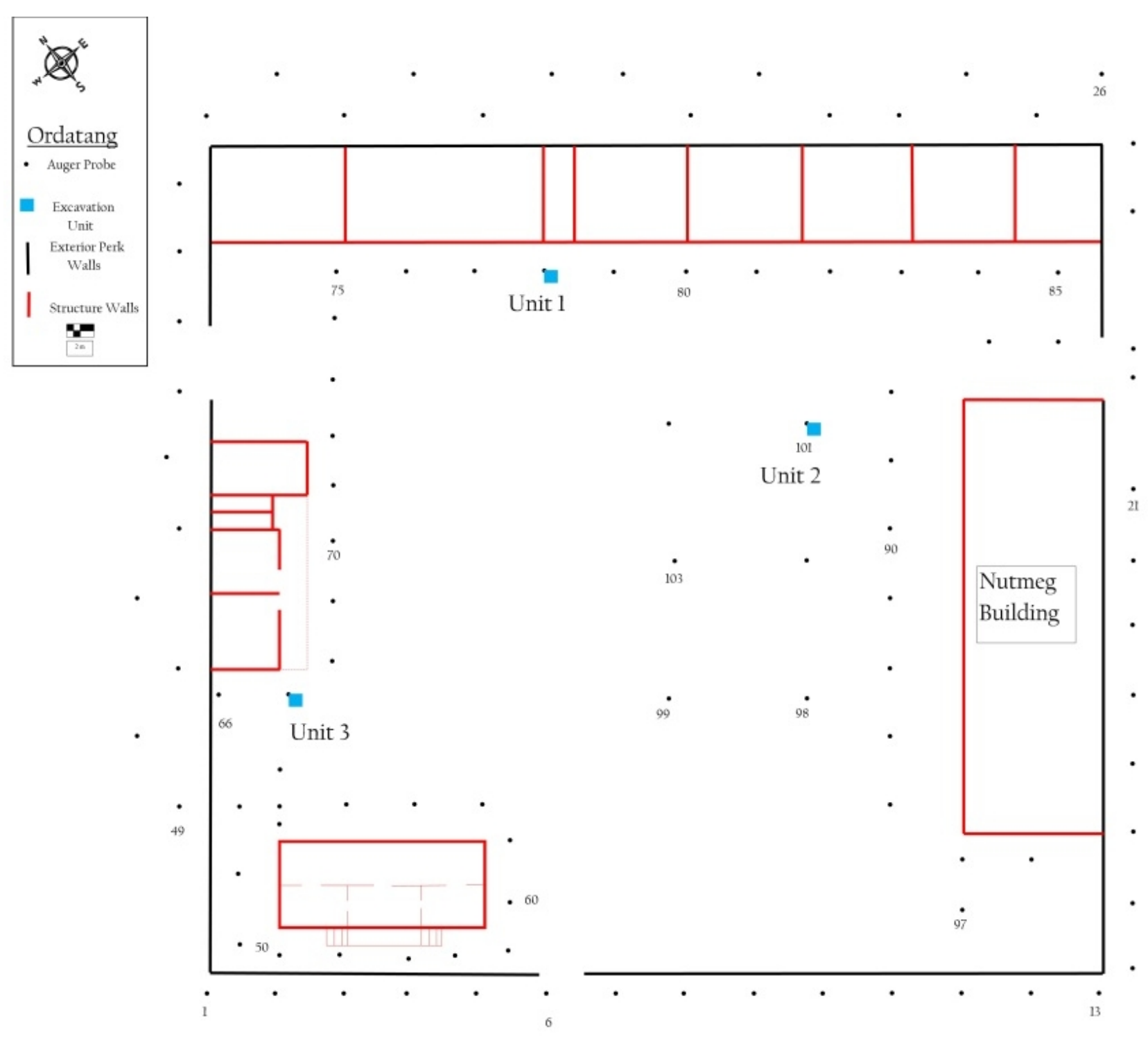

Figure 3: Ordatang site map.

of the structure. One side is reserved for the nutmeg drying barn, another for the colonial house, and the final two had long structures divided into rooms. These structures may have been used for storage or workers' housing. An auger probe survey was conducted both outside the walls and within the compound in an attempt to locate artifact concentrations; $1 \mathrm{~m} \mathrm{x} 1 \mathrm{~m}$ units were then placed in areas of highest artifact density (See Figures 3-5 for auger probes and unit locations). Units were excavated in $10 \mathrm{~cm}$ levels up to $1 \mathrm{~m}$ or bedrock. While Lape (2000) did discover colonial era deposits up to $2 \mathrm{~m}$ or more at sites on Banda Neira, diminishing amounts of porcelain and tradeware with depths at all three Banda Besar sites does indicate the entire colonial era deposit was recovered and pre-colonial deposits were reached at a depth of $1 \mathrm{~m}$.

Due to the modern construction at Komber, the stratigraphy there was mixed for all units. Two of the units at Groot Waling also appear to be mixed, based on refits between ceramics and bone. Therefore, most of my con- clusions can only be general as there is little chronological control.

\section{METHODS}

\section{Ceramics}

Ceramics followed standard methodology (Rice 1987). Sherds were measured and weighed and temper was identified. Vessel part was noted and any decoration was recorded.

\section{Faunal}

Faunal analysis also followed standard methodology (Reitz and Wing 1999). Faunal remains were identified to lowest taxonomic level, counted, and weighed. Faunal remains were fragmentary and an appropriate comparative collection for local fish does not exist, so very often remains could only be identified to class or family. Due to the remote location of these islands, there is a paucity of 


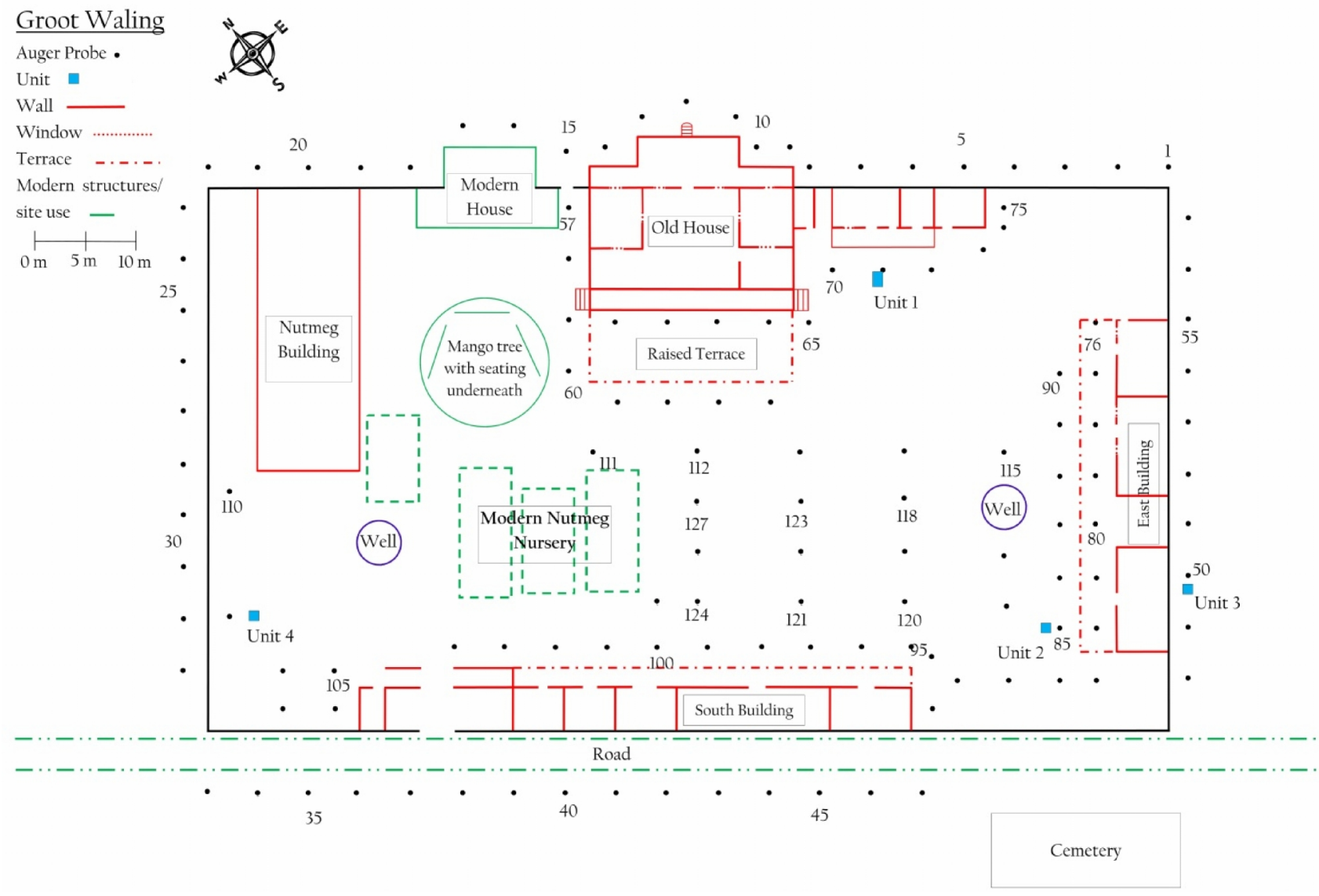

Figure 4: Groot Waling site map.

endemic fauna so identification to large mammal vs small mammal or fish was generally sufficient to produce meaningful data. Only vertebrate fauna were included in this analysis as it was impossible to determine if marine and terrestrial shell was archaeological or environmental.

\section{Starch}

Starch grain extraction followed the protocol established by Judith Field (2008) and was conducted at the University of New South Wales thanks to a NSF EAPSI grant. Sherds were submerged in distilled water and sonicated for 1 minute to remove adhering soils and residues. No attempt was made at this time to distinguish starch from soil versus adhering to the pot, see below ("Results") for discussion of this issue. This water and soil slurry was strained through a $125 \mu \mathrm{m}$ sieve. The $<125 \mu \mathrm{m}$ sample was then centrifuged for 3 minutes to concentrate the sample. The concentrated sample then underwent heavy liquid separation using sodium polytungstate to separate the starch. The sample was rinsed with water after heavy liquid separation and dried using acetone. The dried sample was then mixed with glycerol and mounted on microscope slides; finally, a cover slip was placed over the sample and sealed with clear nail polish.

No attempt was made at this time to identify cooked starches via staining. Upon completion of the earthenware analysis, only 70 of 3603 earthenware sherds (1.9\%) had evidence of charring. The low number of sherds with evidence of cooking starchy foods coupled with financial and time constraints led me to conclude this would not be a fruitful line of inquiry at this timebut may be useful for future projects.

A comparative collection of historically mentioned starches, including rice (Oryza sativa and Oryza sativa japonica), sago (Metroxylon sagu), cassava (Manihot esculenta), white potato (Solanum tuberosum), sweet potato (Ipomea batatas), yam (Dioscorea esculenta), taro (Colocasia esculenta), corn/ maize (Zea mays), nutmeg (Myristica fragrans and Myristica ssp.), and kenari ( $\mathrm{Ca}$ narium ovatum) was also created. The comparative collection was created following Field (2006: 109-11); botanical samples were crushed in a mortar and pestle and mounted on slides in a $50 \%$ glycerol/ water solution.

\section{RESULTS}

As this paper is intended to be a general review of results, the specifics of the detailed analyses are not presented here but can be found in my dissertation (Jordan n.d.).

\section{Ceramics}

Two major types of temper were identified in the assemblage: "grit" and "shell" (Figure 6). I defined grit as poorly sorted mineral and/ or grog temper. These sherds were often thicker, fired in a reducing atmosphere, and are older (Spriggs 1990). "Shell" temper is more accurately 


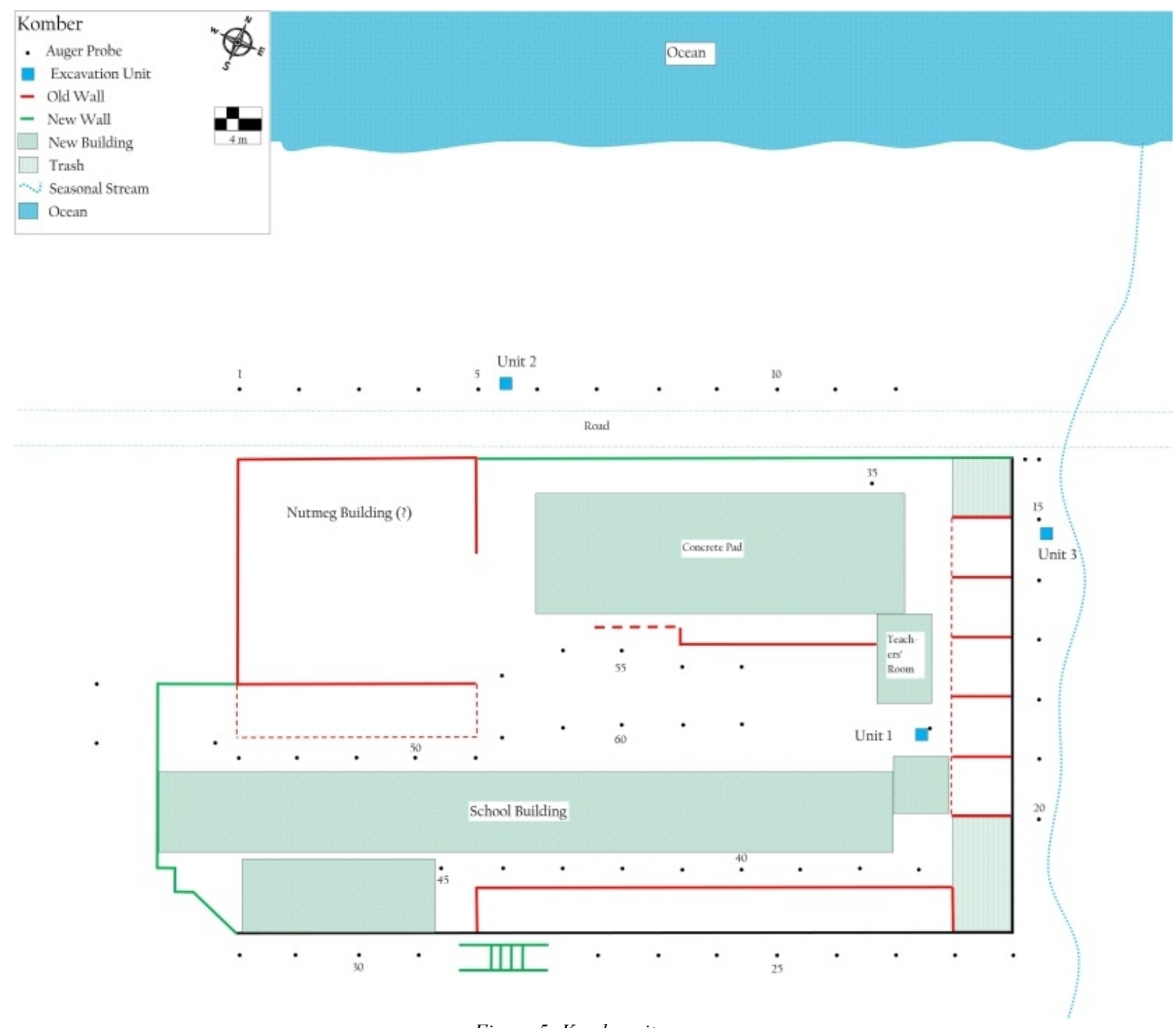

Figure 5: Komber site map.

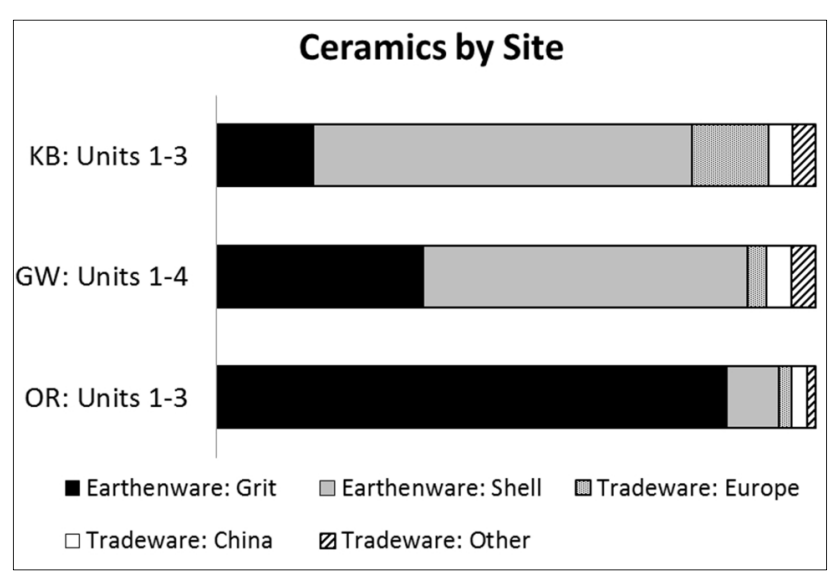

Figure 6: "Shell" vs "Grit" temper by Site.

foraminifera temper, but it is a calcareous material. "Shell" temper sherds are generally thinner, fired in an oxidizing atmosphere, and are younger (Spriggs 1990).
Based on Lape (2000) and Shiung (2011), some of the "grit" tempered wares may be locally produced, but explicit sourcing has yet to be conducted. The "shell" tempered sherds are imported from the Ambon-Lease region (Spriggs and Miller 1979), but additional chemical sourcing would yield more accurate sources. There is a definite difference in temper distribution at the three sites with "grit" temper dominating at Ordatang and "shell" dominating at Komber and Groot Waling. Unfortunately, the sites do not have sufficiently intact stratigraphies and these ceramics do not have tight chronological control according to current research. However, TL dates (Table 2) conducted by the UW Luminescence Laboratory do suggest that the "grit" temper pre-dates the "shell" temper, as postulated by Spriggs (1990). The "grit" temper does appear to be replaced by "shell" temper at Groot Waling, making it look like there was a replacement over time (Figure 7), at least at this site. "Shell" temper dominates the two coastal sites but is rare at the interior site. It is possible that the "grit" temper represents a pre-colonial 
Table 2: TL dates for plantation earthenware sherds, after Feathers (2014).

\begin{tabular}{|c|c|c|c|c|c|c|}
\hline Sample & Site/ level & temper & Age (ka) & $\%$ error & Basis for age & Calendar date (years BC/AD) \\
\hline UW2643 & OR Unit $10-10-\mathrm{cm}$ & grit & $3.56 \pm 0.62$ & 17.5 & OSL/IRSL & BC $1550 \pm 620$ \\
\hline UW2644 & OR Unit $190-100-\mathrm{cm}$ & grit & $3.79 \pm 0.34$ & 8.9 & Uncorrected TL & BC $1780 \pm 340$ \\
\hline UW2645 & GW Unit 2 & grit & $\begin{array}{l}0.80 \pm 0.06^{*} \\
0.12 \pm 0.02^{*}\end{array}$ & $\begin{array}{c}7.6 \\
20.8\end{array}$ & $\begin{array}{c}\text { IRSL } \\
\text { Uncorrected TL }\end{array}$ & $\begin{array}{l}\text { AD } 1220 \pm 60 \\
\text { AD } 1900 \pm 20\end{array}$ \\
\hline $\begin{array}{l}\text { UW2646 } \\
\text { UW2647 } \\
\text { UW2648 }\end{array}$ & $\begin{array}{l}\text { GW Unit 290-100 cm } \\
\text { KB Unit } 20-10 \mathrm{~cm} \\
\text { KB Unit } 290-100 \mathrm{~cm}\end{array}$ & $\begin{array}{l}\text { grit } \\
\text { grit } \\
\text { shell }\end{array}$ & $\begin{array}{c}7.66 \pm 1.26^{\star *} \\
9.91 \pm 1.14^{\star *} \\
1.14 \pm 0.21\end{array}$ & $\begin{array}{l}16.5 \\
11.5 \\
18.4\end{array}$ & $\begin{array}{c}\text { OSL/uncorrected TL } \\
\text { OSL/uncorrected TL } \\
\text { OSL }\end{array}$ & $\begin{array}{c}\text { BC } 5650 \pm 1260 \\
\text { BC } 7900 \pm 1140 \\
\text { AD } 870 \pm 210\end{array}$ \\
\hline
\end{tabular}

* Likely under-estimated.

** Likely over-estimated.
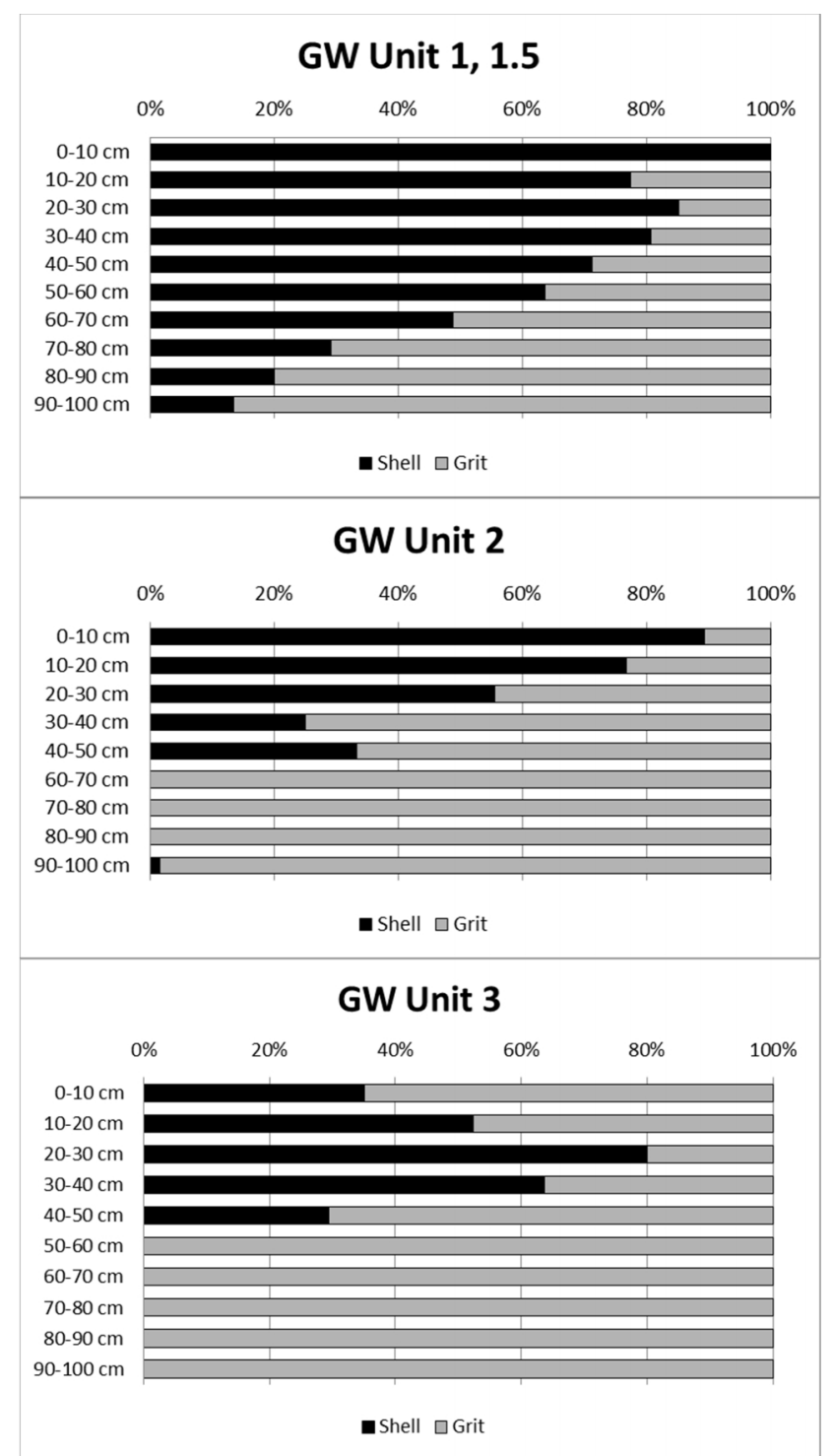

Figure 7: "Shell” vs “Grit” temper by unit at Groot Waling.

ceramic tradition, possibly from both local traditions and trade routes. Based on Lape's (2000) previous work, however, "shell" tempered pottery appears after c. AD 1200 in the Banda Islands and continues after the colonial period (Shiung 2011). This date is supported by the TL determination on the shell tempered sherd from Komber; both suggest a pre-colonial adoption of "shell" tempered pottery in the Banda Islands. This indicates that colonial occupation did not drastically change established trade patterns in Banda. At least one colonial era site excavated by Lape (2000, Shiung 2011) did not produce any "shell" tempered pottery, which could indicate different trading partners for contemporary villages or differential access to imported ceramics.

Based on the ceramic data, despite the purported political control of the Dutch in the Banda Islands, the established trade routes were not affected. Even though the Bandanese populations were decimated, historical records don't discuss the destruction of the numerous nonBandanese traders who lived in Banda. Chinese, Javanese, Arab, and other traders are often mentioned in historic records (Hanna 1978, Ellen 2003). The continuity of these traders in Banda may have led to the maintenance of the pre-colonial trade routes during Dutch occupation. Ellen (2003) did note the Dutch had to maintain trade routes for their own survival and the ceramic data from the plantation sites and Lape's (2000) village sites supports this.

\section{Faunal}

Figure 8 shows the faunal assemblages for the three plantations sites. Due to the mixed stratigraphy, the low number of recoverable remains, and the fragmentary nature of the recovered remains, the faunal assemblages are presented for the entire site and as both mass in grams and count. Mammal bone weighs more than other classes and thus appears to dominate; numerically, however, fish vertebrae dominate the assemblage. Faunal remains are generally fragmentary, but for mammals, cranial, teeth, metacarpals and metatarsals, and long and flat bone fragments are present at all sites. Cranial, fin, and vertebrae are present for fish. The fish vertebrae and other bones were small and probably represent reef fish as opposed to pelagic species. The small size does indicate a low investment in catching these fish. At least one rib fragment showed signs of having been digested, presumably by a scavenging dog or possibly pig. The presence of all the elements suggests whole animals were being slaughtered at the site or nearby and elements shared among the residents. The paucity of remains and fragmentary nature result in a minimum of one pig, one cow, one goat, for each individual site, but also for all sites combined. This supports more of an energetic efficiency model for the consumption of animal protein. That is, inhabitants of the 
perken took easy prey in the case of whole, small, reef fish and supplemented with the very occasional whole domesticated mammal.

\section{\% Faunal Remains by Site by Weight} (g)

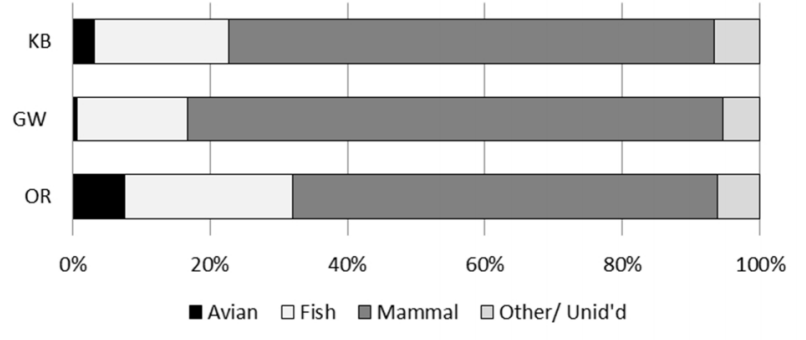

\section{\% Faunal Remains by Site by Count}

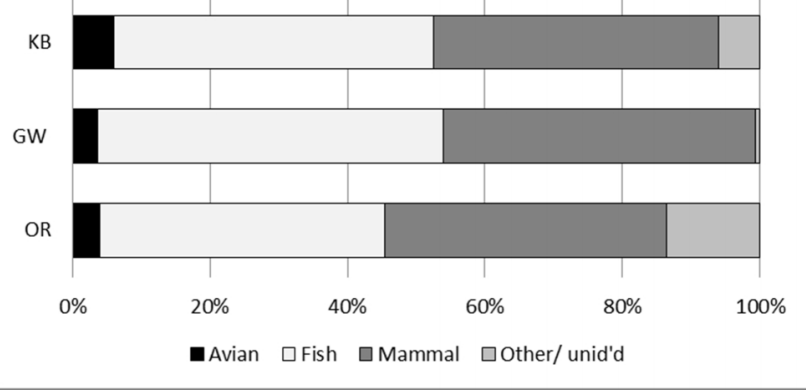

Figure 8: Faunal distribution by site.

\section{Starch}

For the preliminary study of starch, only 1 slide for each sample was mounted and examined. The preliminary starch grain analysis produced starch in about $20 \%$ of the 108 samples. Of the 16 porcelain sherds, 5 (31\%) produced starch and 17 of the $92(15 \%)$ earthenware sherds produced starch. The preliminary analysis suggested that starch was present in low quantities.

For subsequent analysis, the entirety of 74 samples (12 porcelain, 62 earthenware) were mounted and examined. For many levels, two sherds had been retained unwashed for analysis, for the subsequent analysis only one sherd was selected for sample mounting as redundancy had been noted at this time. A total of 1527 slides were mounted, 108 for the pilot study and 1419 for the secondary analysis. An average of 30 slides per sample was produced. For the complete analysis, 778 total starch grains were observed. The analysis showed that a majority $(93 \%$ of the 74 samples) of the samples did contain small amounts of starch. However, only 338 of the 1527 slides produced starch, thus only $22 \%$ of the total slides produced starch, similar to the preliminary pilot study. So while a majority of samples did contain starch, starch grains were present in low numbers for these samples. The number of grains per sample ranged from $0-165$, but $54 \%$ of the samples produced 5 or fewer grains and $80 \%$ of the samples produced 10 or fewer grains. Please see supplementary material for details of starch results.
Of the 69 porcelain and earthenware sherds with starch, only four produced rice grains (Figure 9). This is notable as rice should have been the predominant starch based on historically recorded preference. All four sherds, two porcelain and two earthenware, produced both rice and non-rice starch grains. The fact that rice grains were found on both earthenware and porcelain indicates that both the "elite" and "non-elite" ceramics were used for serving rice. But the presence of non-rice grain shows that the "elite" porcelain was also being used in association with lower status starches in addition to lower status earthenware being used for high status starch. This mixing of starches and ceramic types suggests a creolization of this aspect of the diet at the plantations. However, the lack of intact stratigraphy and the shallow depth of the sherds with rice grains may suggest that this "creolization" could be a recent phenomenon. The four sherds that did produce rice grains were found in the upper $0-20 \mathrm{~cm}$ of the sites, suggesting that the rice residue is, in fact, from a more recent, possibly contemporary, deposition and may not reflect the colonial diet. The presence of starch grains in the deeper levels suggests that the lack of rice grains cannot be due to taphonomic processes.

Historic records suggest sago should have been the local replacement, but sago has not been identified in the samples. There are 71 starch grains whose size overlaps that of the sago in the comparative collection (24.14$73.47 \mu \mathrm{m}$ ), but only 6 of the 71 starch grains (Figure 10) have an eccentric hilum and 4 of these 6 are below the average size $(45.28 \mu \mathrm{m})$ of the comparative sago starch grains. One of the starch grains which matches in size, shape, and hilum is more likely potato (Solanum tuberosum). The shape and size are not consistent with the sago in the comparative collection. None of the starches, other than rice, from the comparative collection appear to match the archaeological starches. So while four of the 69 samples did produce rice, the remaining starch grains cannot be identified as historically recorded starches present in the Banda Islands, at this time. Additional research identifying edible local plants would be most useful to identify potential starch sources.

Crowther (2005) notes that starch grains can be found in soil in activity areas of starch processing. Due to international import laws, I was not able to retrieve soil samples for starch testing. Thus, it could be argued, that the unidentified starch remains are the result of background starch within the soil and not the result of pottery use. Due to the different environments of the sites (highland kenari/ nutmeg forest and beach), it is unlikely that the same starch producing plant could be found in both environments, lessening the potential for environmental contamination. If the starch remains on the sherds are a result of soil transfer, it should still reflect human activity and human diet. However, a recent article (Crowther et al. 2014) suggests that laboratory contamination could result in a positive result for the existence of starch. Corn (Zea mays), wheat (Triticum and Aegilops), barley (Hordeum), potato (Solanum tuberosum) and non-specific grasses (Poaceae) are the most common starches found to create 

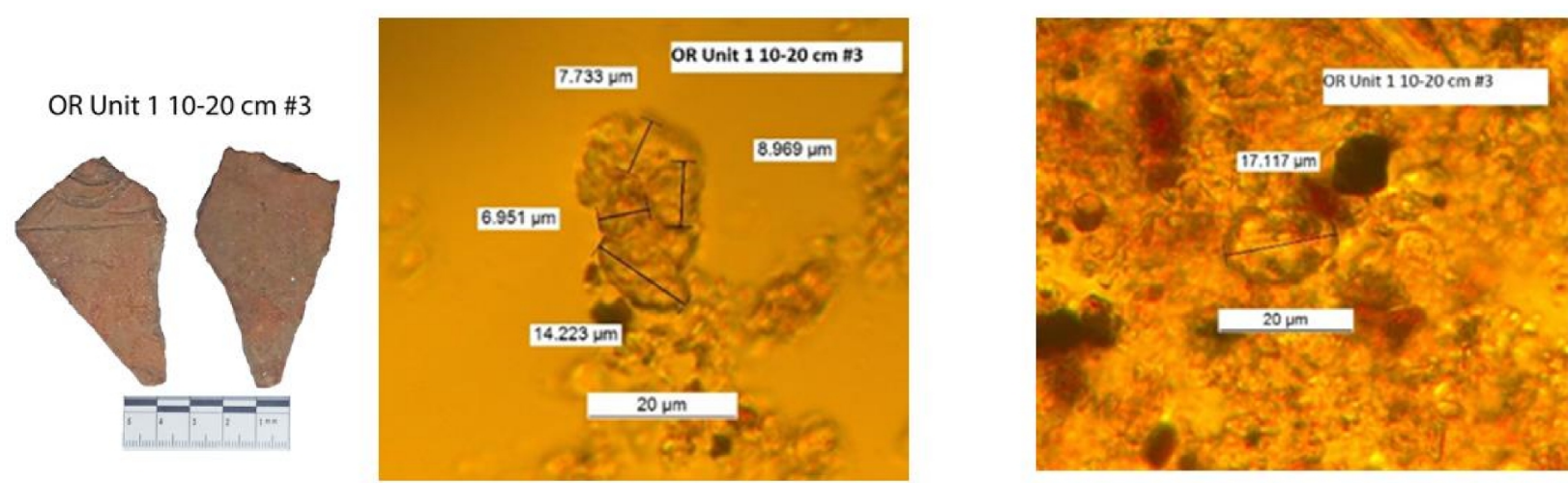

OR $20-10 \mathrm{~cm} \mathrm{pl}$
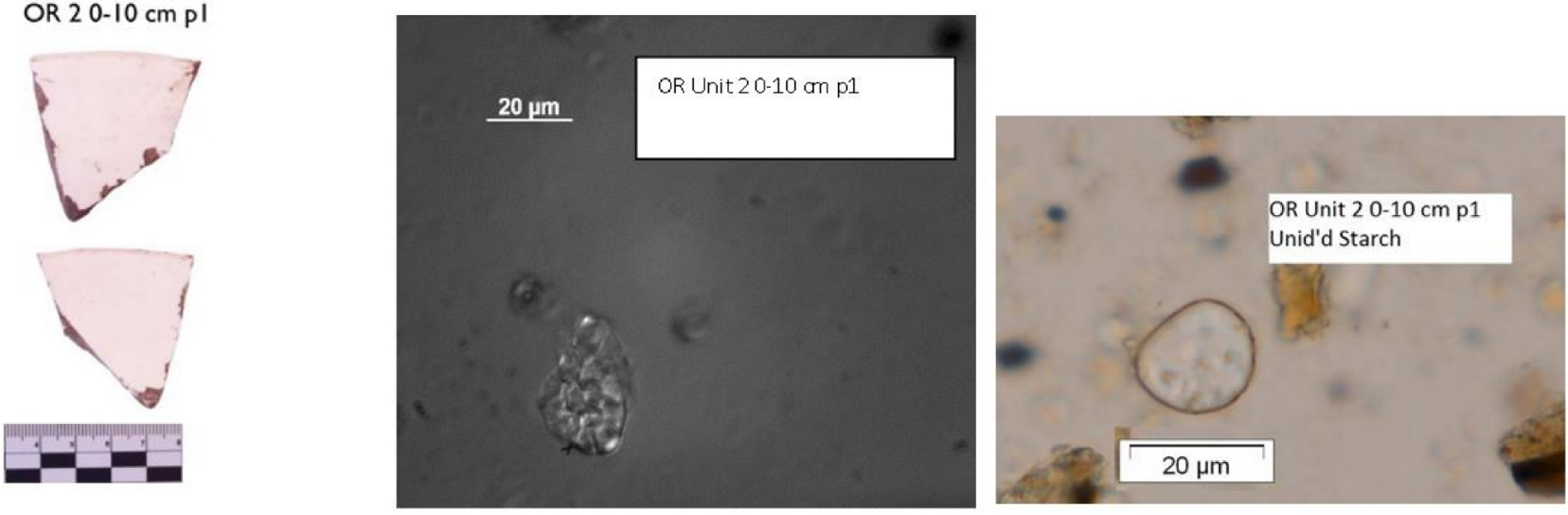

OR 2 I0-20 cm p2

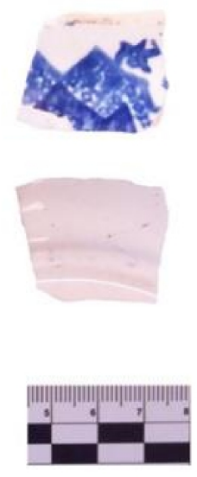

Banda 2011

GW Unit $110-20 \mathrm{~cm} \# 2$

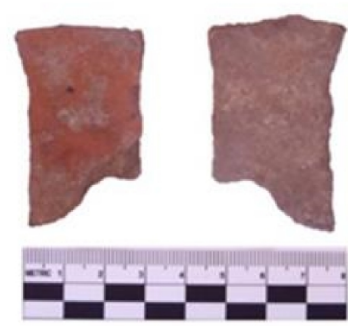

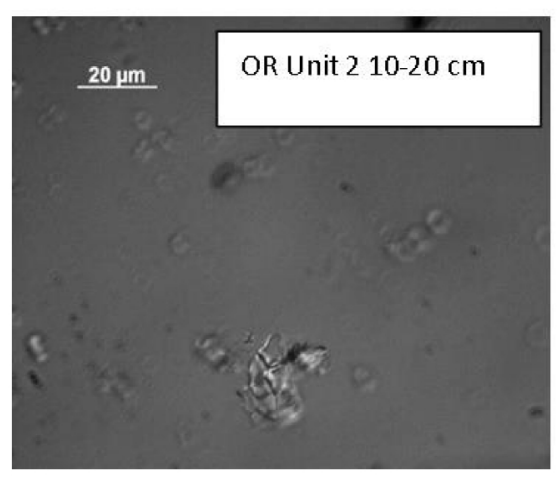

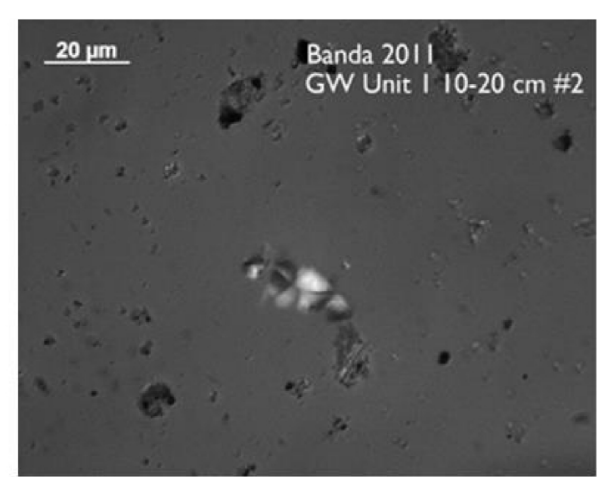

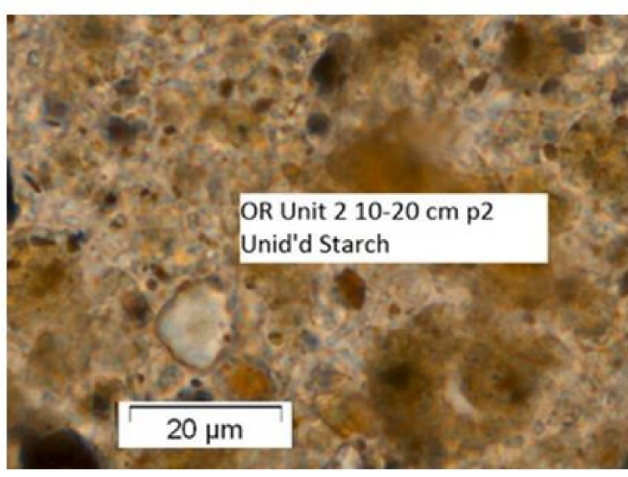

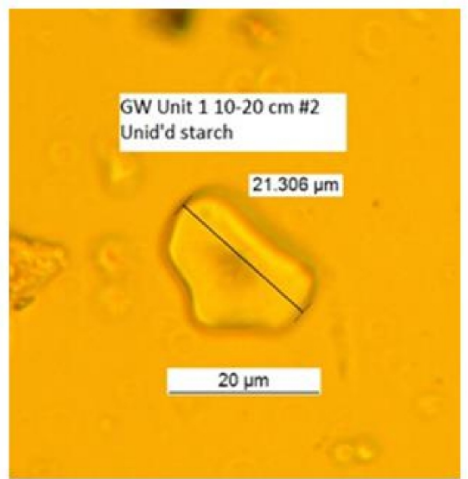

Figure 9: Rice grains and associated sherds. 

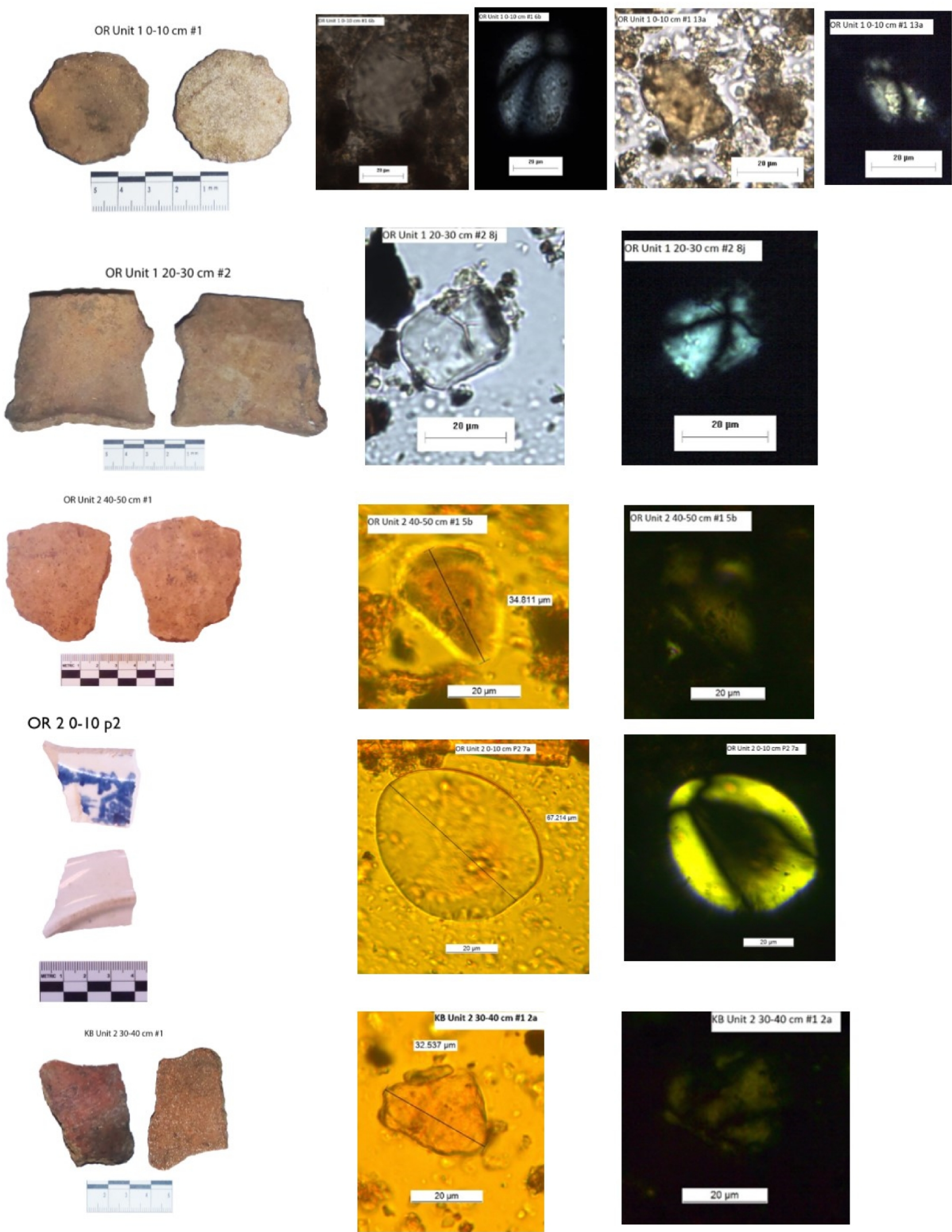

Figure 10: Starch grains that overlap in size and shape with sago, non-polarized and polarized.

laboratory contamination. These potential contaminants do not appear to match the majority of the unidentified starches in the Banda collection, based on those in the comparative collection (Zea mays and Solanum tuberosum) and published photos and descriptions of those 
not in the comparative collection, but laboratory contamination cannot be wholly ruled out.

Interestingly, at a very basic level, it does not appear that earthenware pottery was primarily used to cook or serve starches in general and specifically not the historically recorded starches. Very little information is available regarding earthenware use, manufacture, trade, or sources in Maluku (Latinis and Stark 2003). Additional information regarding where the earthenware pots originally came from may elucidate their function. However, it does not change the fact that the expected, historically recorded starches were not found on the archaeological sherds, suggesting that the ceramics were not used for storing, cooking, or serving the starches that European records claim were most prevalent on the islands. The lack of charring on earthenware sherds also supports the idea that they were not used for cooking starchy foods that would leave a residue. Non-ceramic cooking methods are certainly still in use today in the general region and on the Banda Islands in particular, so this absence need not be a surprise. In his 1544 voyage to Maluku, Galvao (Jacobs 1970:141) note residents "make little use of pots; for they cook meat, fish, and all other necessities in vessels of cane[bamboo]", again supporting the idea that earthenware was not used for cooking starchy staples. More research needs to be done on the use of ceramics in Island Southeast Asia in general.

\section{DISCUSSION}

\section{Comparison to other Banda Sites}

Plantation sites were described as elite residences in the historical literature (e.g., Hanna 1978), but few elite artifacts were found at the plantations. In order to determine whether the lack of elite artifacts was due to their function at the site or lack of imported material, I compared the plantation ceramic assemblages to sites previously excavated by Lape (2000) (Figure 11). It should be noted that Lape excavated $2 \mathrm{~m}$ x $2 \mathrm{~m}$ units while I excavated $1 \mathrm{~m} \times 1$ $\mathrm{m}$ units, thus I have used percentages to compare, but the number of sherds is noted in the supplemental material. The top three sites are the plantations; the next two sites are the governor's mansion (BN 4) and the Harmonie Social Club (BN 2) on Banda Neira. The bottom two bars represent the assemblage from a village site on Banda Neira (BN 1), separated into colonial (Col) and precolonial (PC) eras. There are significantly more pipes (numbering in the hundreds) and tradeware/ porcelain found at the known elite residences (BN 2 and $\mathrm{BN} 4$ ). However, there are less than 5 pipe fragments at each of the other sites and less than 200 tradeware sherds, making up less than $20 \%$ of the assemblage. While tradeware makes up less than $30 \%$ of the assemblages at all sites, the sheer amount of tradeware $(n=872$ at BN2 and $n=1817$ at $\mathrm{BN} 4$ ), even accounting for the larger unit size, is quite high in comparison to the plantations. The plantation assemblages match the village site assemblage (BN1) more so than it does the elite residences. The lack of elite goods- especially pipe fragments- at the plantations, in comparison to the known elite residences does suggest that the European perkeniers were not spending a lot of time at the plantations and the plantation assemblages were more closely related to villages. Despite the historical claims for the plantations as elite residences, the artifact assemblages suggest that perkeniers probably spent more time at their houses in the main port of Banda Neira than at the plantations.

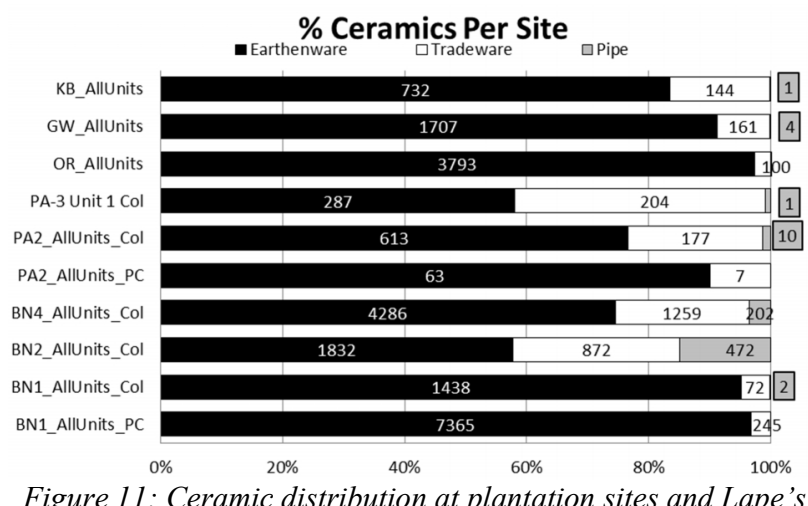
(2000) sites.

\section{CONCLUSION}

Interpretations of indigenous peoples' reaction to colonization often tend to focus on one aspect of material culture, be it ceramics, faunal remains, or spatial organization. By looking at multiple lines of evidence, different interpretations of the material culture arise. For the Banda Islands plantation sites, faunal remains tend to reflect a more optimal foraging/ energetic efficiency strategy where residents were eating either the low cost fish or utilizing the entirety of domesticated mammals. Starch remains may show creolization with both elite rice and non-elite other starch grains being found on the assumed elite porcelain. The elites may have been using porcelain/ tradeware for both rice and lower-ranked starches, or the workers accessed the porcelain and had access to both rice and non-rice grains. The shallow depth of the porcelain, however, suggests a recent deposit; perhaps residents were more willing to embrace a creolized diet in the modern era. Regardless of who was using the dish, the mixing of rice and non-rice grains shows a creolization of starches. Since the majority of starches found on the ceramics could not be identified to historically recorded starches, it is possible that the use of local, unrecorded starches may also reflect an optimal foraging strategy, but more research into floral resources on the Banda Islands needs to be conducted. The earthenware ceramics, on the other hand, shows a continuation of pre-colonial trade routes and when starch was present, and that the starches present are unmentioned in colonial historic sources.

Investigating only one category of material culture would have given a limited view of the effect of colonialism on the inhabitants of the Banda Islands. Instead, it is evident that there was no one monolithic reaction to colonialism. Conservatism of material culture and creolization of diet were both utilized as strategies on the plantations of colonial period Banda Islands. In addition, the compar- 
ison of the plantation assemblages to known elite residences, suggests that the plantations were not the theatre of social negotiation but the material culture instead more closely allied with pre-colonial village life.

\section{ACKNOWLEDGMENTS}

Special thanks to: Peter Lape, Judith Field and BEES staff at UNSW, Balai Arkeologi Ambon, Daud Tanudjiro , Sopyan \& Ayup, Ponky van den Broecke and family, Jen Zachanowich and Guillaume Lozeau, the residents of ICRS Guesthouse Yogyakarta, Oishee Alam and Will Scates Frances, and Zena Kassir. This research was partially funded by an ACLS/ Luce fellowship and NSF EAPSI fellowship.

\section{REFERENCES}

Barton, H. and R. Torrence. 2006. Preface. In Ancient Starch Research, R. Torrence and H. Barton, editors, pp. 17-34. Walnut Creek, CA: Left Coast Press.

Bellwood, P. 1997. Prehistory of the Indo-Malaysian Archipelago. Honolulu: University of Hawaii Press.

Bliege Bird, R. and D.W. Bird. 1997. Delayed reciprocity and tolerated theft: the behavioral ecology of food sharing strategies. Current Anthropology 38: 49-78.

Bliege Bird, R. and E. A. Smith. 2005. Signaling Theory, Strategic Interaction, and Symbolic Capital. Current Anthropology 46: 221 .

Chaudenson, R. 2001. Creolization of language and culture. Translated by S. S. Mufwene. Routledge, London

Crowther, A. 2005. Starch residue on undecorated Lapita pottery from Anir, New Ireland. Archaeology in Oceania 40: 6266.

Crowther, A., M. Haslam, N. Oakden, D. Walde, J. Mercader, 2014. Documenting contamination in ancient starch laboratories. Journal of Archaeological Science 49: 90-104.

Deagan, K 1991. Historical archaeology's contributions to our understanding of early America. In Historical Archaeology in Global Perspective, Lisa Falk, editor, pp. 97-112. Washington, DC: Smithsonian Press.

Deetz, J.1991. Introduction: Archaeological Evidence of Sixteenth and Seventeenth-Century Encounters. In Lisa Falk, editor, Historical Archaeology in Global Perspective,pp. 1-9. Washington, DC: Smithsonian Press.

Diehl, M., J. A. Waters, and J. H. Thiel. 1998. Acculturation and the Composition of the Diet of Tuscon's Overseas Chinese Gardeners at the Turn of the Century. Historical Archaeology 32: 19-33.

Ellen, R. F. 2003.On the edge of the Banda zone: past and present in the social organization of a Moluccan trading network. Honolulu: University of Hawaii Press.

Feathers, J. 2014. Luminescence analysis of pottery from Banda Islands, Indonesia. Unpublished report.

Field, J. 2008. Starch analysis of archaeological samples- pot sherds from the early Neolithic Site PA1, Banda Islands, Indonesia, (c. 2-3 kaBP). Unpublished report prepared for Dr. Peter Lape.

Foucault, M.1979. Discipline and punish: the birth of the prison. New York: Vintage Books.

Franklin, M. 2001. The archaeological dimensions of soul food: interpreting race, culture, and Afro-Virginian identity. In
C. E. Orser, editor, Race and the archaeology of identity, pp. 88-107. Foundations of archaeological inquiry, J. M. Skibo, general editor. Salt Lake City: University of Utah Press.

Gould, R.A. 1980.Living Archaeology. Cambridge: Cambridge University Press.

Hanna, W. A. 1978. Indonesian Banda: colonialism and its aftermath in the Nutmeg Islands. Philadelphia: Institute for the Study of Human Issues.

Hilliard, S.B. 1988.Hog meat and cornpone: Foodways in the Antebellum South. In R.B. St.George, editor, Material Life in America, 1600-1860, pp. 311-332. Boston: Northeastern University Press.

Jacobs, H. 1970. A Treatise on the Moluccas (c.1544). Rome: Jesuit Historical Institute.

Janowitz, M. F. 1993.Indian Corn and Dutch Pots: Seventeenth Century Foodways in New Amsterdam/ New York. Historical Archaeology 27: 6-24.

Jolley, R. L. 1983.North American Historic Sites Archaeology. Historical Archaeology 17: 64-79.

Jordan, A.J. n.d. The Price of Spice: Ethnogenesis in Colonial Period Banda Islands, Indonesia. Unpublished PhD dissertation, Department of Anthropology, University of Washington.

Khan, A. 2007.Good to Think? Creolization, Optimism, and Agency. Current Anthropology 48: 653-674.

Lape, P. V. 2000 Contact and conflict in the Banda Islands, Eastern Indonesia, $11^{\text {th }}-17^{\text {th }}$ centuries. Unpublished $\mathrm{PhD}$ dissertation, Department of Anthropology, Brown University.

Loth, V. C. 1998. Fragrant gold and food provision. In S. Pannell and F. von Benda-Beckman, editors, Old World Places, New World Problems, pp.66-93. Canberra: Center for Resource and Environmental Studies.

Ptak, R. 1991. From Quanzhou to the Sulu Zone and beyond: questions related to the early fourteenth century. Journal of Southeast Asian Studies 29: 269-294.

Reitz, E. and E. Wing. 1999. Zooarchaeology. Cambridge: Cambridge University Press.

Reitz, E. J., T. Gibbs and T. A. Rathburn. 1985. Archaeological Evidence for Subsistence on Coastal Plains. In T.A. Singleton, editor, The Archaeology of slavery and plantation life, pp. 463-194. Orlando: Academic Press.

Rice, P. 1987. Pottery Analysis: A Sourcebook. Chicago : University of Chicago Press.

Ricklefs, M. 2001. A History of Modern Indonesia since c. 1200. Stanford, CA: Stanford University Press.

Schmitt, D. N. and C. D. Zeier. 1993.Not by bones alone: exploring household composition and socioeconomic status in an isolated historic mining community. Historic Archaeology 27: 20-38.

Scott, E. M. 2001. Food and Social Relations at Nina Plantation. American Anthropologist 103: 671-691.

Shiung, C.C. 2011. The implications of social, cultural, econom$i c$, and political interactions for ceramic evolution on the Banda Islands, Maluku Province, Indonesia. Unpublished $\mathrm{PhD}$ dissertation, Department of Anthropology, University of Washington.

Spriggs, M. 1990. Archaeological and ethnoarchaeological research in Maluku 1975 and 1977: an unfinished story. Cakalele 1: 49-60. 
Spriggs, M. and D. Miller. 1979. Ambon-Lease: on study of contemporary pottery making and its archaeological relevance. In Pottery and the archaeologist, Occasional Publication No.4, M. Millett, editor, pp. 25-34. London: Institute of Archaeology.

Stark, K. and K. Latinis. 1992. The Archaeology of sago economies in Central Maluku: An initial sketch. Cakalele 3: 69-86.

Stewart, C. 2007. Creolization: History, Ethnography, Theory. In C. Stewart, editor, Creolization: History, Ethnography, Theory, pp. 1-25. Walnut Creek, CA: Left Coast Press.

Stoler, A. L. 1985 Capitalism and confrontation in Sumatra's plantation belt, 1870-1979. New Haven: Yale University Press.

Voss, B. L. 2008. The Archaeology of Ethnogenesis: race and sexuality in colonial San Francisco. Berkeley: University of California Press.

Winn, P. 2002. 'Everyone searches, everyone finds': Moral discourse and resource use in an Indonesian Muslim community. Oceania: 72: 275-292.

Winn, P. 2010. Slavery and cultural creativity in the Banda Islands. Journal of Southeast Asian Studies 43: 365-389.

Winterhalder, B. and E. A. Smith. 2008.Evolutionary Ecology and the Social Sciences. In E. A. Smith and B. Winterhalder, editors, Evolutionary Ecology and Human Behavior, $2^{\text {nd }}$ edition, pp. 3-24. New Brunswick: Aldine Transaction.

Wolf, E. R. 1982. Europe and the People Without History. Berkeley: University of California Press. 